\title{
Management of Ectodermal Dysplasia with Tooth Supported Complete Overdentures: A Case Report
}

\author{
Muhammad Waseem Ullah Khan ${ }^{1}$ \\ Momina Akram² \\ Sabiha Naeem ${ }^{3}$ \\ Ruksana Akram ${ }^{4}$ \\ BDS, FCPS \\ BDS, FCPS \\ BDS \\ BDS
}

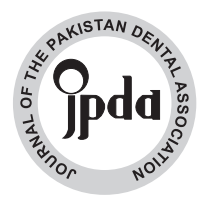

Ectodermal dysplasia is a hereditary disease characterized by abnormal development of structures derived from embryonic ectoderm. Prosthetic rehabilitation of patients with ectodermal dysplasia is challenging. In this case report, a 19-year-old male was diagnosed with ectodermal dysplasia. His oral functions, esthetics and phonetics were successfully restored with upper and lower complete overdentures which greatly improve the psychological status of the patient.

KEY WORDS: Ectodermal dysplasia, overdentures, prosthodontic rehabilitation.

HOW TO CITE: Khan MWU, Akram M, Naeem S, Akram R. Management of ectodermal dysplasia with tooth supported complete overdentures: A case report. J Pak Dent Assoc 2019;28(4):201-203.

DOI: https://doi.org/10.25301/JPDA.284.201

Received: 29 March 2019, Accepted: 24 June 2019

\section{INTRODUCTION}

$\mathrm{E}$ ctodermal dysplasia comprises of a spectrum of inherited disorders due to abnormalities in the tissue derived from the embryonic ectoderm including Trichodysplasia, Hypodontia/Anodontia, Hypohidrosis/Anhydrosis and Onychodysplasia. ${ }^{1,2}$ More than 170 different nosologic groups of ectodermal dysplasia can be found in the literature but from a clinical standpoint, it can be divided in two major categories. ${ }^{2,3}$ Christ-SiemensTaurine Syndrome is the most common and classical form which is genetically transmitted X-linked recessive trait and presents with hypodontia, hypohidrosis, hypotrichosis and particular faces. ${ }^{4}$ Orofacial manifestations of this syndrome include hypodontia, anodontia, hypo-plastic conical teeth, under development of alveolar ridges, loss of occlusal vertical dimension, prominent supraorbital ridges, frontal bossing, a depressed nasal bridge, protruded lips, hypotrichosis and dry oral mucosa. ${ }^{5}$ The other group is Clauson's syndrome. It is genetically autosomal dominant. It is the hidrotic form of this disease. Prominent feature of this category is unaffected

1. Assistant Professor, Department of Prosthodontics, de'Montmorency College of Dentistry Punjab Dental Hospital, Lahore.

2. Assistant Professor, Department of Prosthodontics, de'Montmorency College of Dentistry Punjab Dental Hospital, Lahore.

3. FCPS Post Graduate Resident, Department of Prosthodontics, de'Montmorency College of Dentistry Punjab Dental Hospital, Lahore.

4. MDS Post Graduate Resident, Department of Prosthodontics, de'Montmorency College of Dentistry Punjab Dental Hospital, Lahore.

Corresponding author: "Dr. Sabiha Naeem" < cute_sabi85@yahoo.com > sweat glands. ${ }^{4,6}$

Different management strategies for the patient of ectodermal dysplasia include removable partial dentures, resin bonded bridges, fixed partial dentures, complete dentures, overdentures and implants retained prosthesis. Choosing the best treatment option for the patient can significantly improve function, appearance and satisfaction. ${ }^{7,8}$ In this case report, we present the treatment option that is not only cost effective for the poor patient but also preserves and maintains the bone which in turn provides retention and stability in the given prosthesis.

\section{CLINICAL REPORT}

A 19-year-old male, a factory worker/laborer by profession, presented to the outdoor of Prosthodontics department at Punjab Dental Hospital, Lahore. His chief complaint was poor esthetics and compromised mastication. After thorough history and examination, a clinical diagnosis of hypohidrotic ectodermal dysplasia was made. He had properly formed finger and toe nails, normal skin, ear and respiratory system. Facial features showed senile appearance with frontal bossing, thin sparse hair on head, face and eyelashes, everted lips, depressed saddle of the nose, bulging at supraorbital area and depressed infraorbital area. Intra-oral examination revealed four permanent teeth (two central incisors and two canines) in the maxillary arch and one tooth (right lower canine) in the mandibular arch (Kennedy's Class I in both arches). All teeth were conical in shape, tilted and spaced 

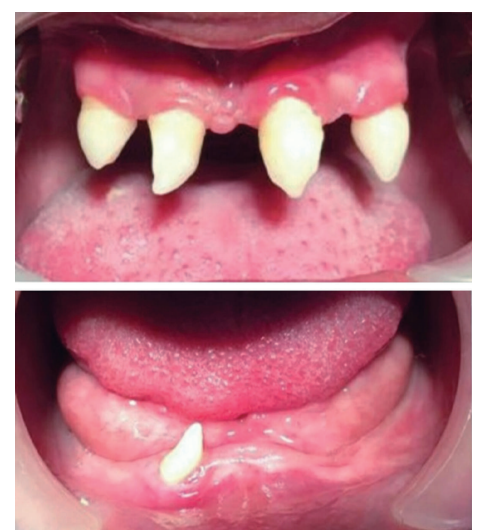

Fig 1

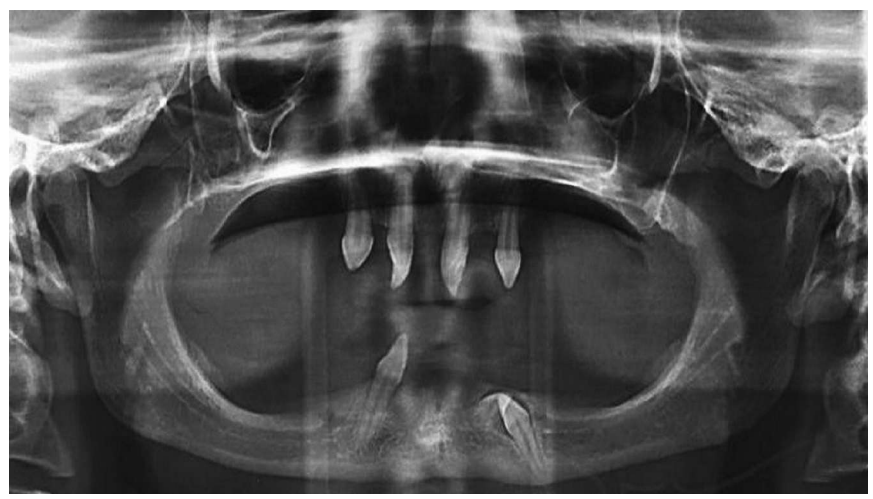

Fig 2
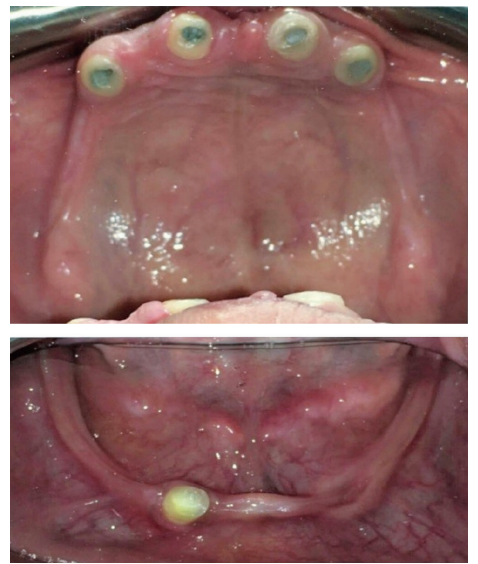

Fig 3

(fig 1). The posterior teeth were not present in both arches so both arches were hypo-plastic, resorbed and under developed. Panoramic radiograph showed impacted left lower canine, atrophic under developed ridges with no other abnormalities (fig.2). Oral mucosa was thin but healthy. Patient's parents, siblings and

relatives were normal not known to have a similar condition. Patient was otherwise medically and mentally healthy.

After the initial assessment, removable upper and lower complete overdentures with endodontic treatment of all upper teeth were prescribed for the patient. Single visit root canal treatment of all upper teeth was done under local anesthesia and dome shaped preparations for overdenture abutments were made. Amalgam fillings were used to restore the endodontically treated teeth. The right lower canine was also prepared in a dome shape to act as an overdenture abutment (fig3). During the preparation of lower canine, the pulp did not expose and signs of sensitivity were also not present, so endodontic treatment of this tooth was not considered necessary. Primary impressions with irreversible hydrocolloid and secondary impressions with eugenol free zinc oxide based impression material were made on the subsequent visits (fig 4).
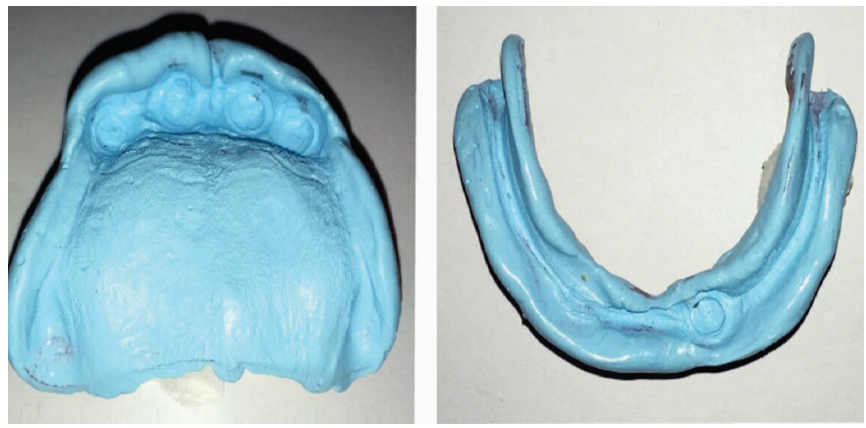

Fig 4

Face-bow records, vertical and horizontal jaw relations were taken as per standard protocols. Articulation and tooth arrangement was done on a semi-adjustable articulator. Bilateral balanced occlusion was provided on average values on the semi adjustable articulator with edge-edge posterior occlusion on left side and cross bite on right side. Such an occlusion was required to keep the posteriors on the center of the ridge and compensates for the constricted maxillary arch and wider maxillary arch in the posterior region. Teeth

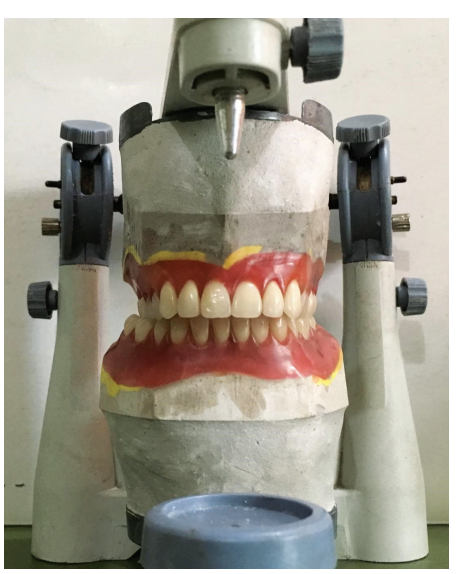

Fig 5 try-in was done on the next visit (fig 5). The dentures were inserted after the necessary tissue surface and occlusal adjustments on the next appointment. The patient was instructed about the care of dentures and retained teeth. He was recommended a high fluoride paste to use twice daily
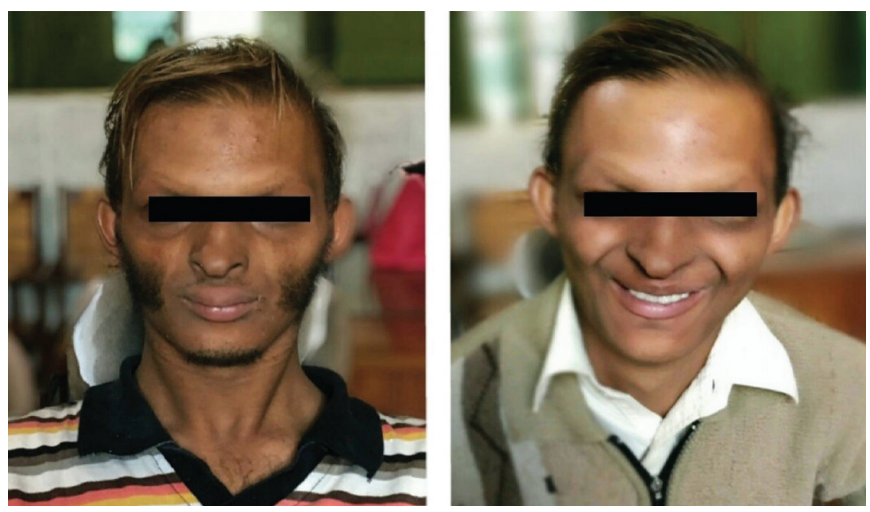

Fig 6

for his natural abutment teeth. The patient was kept under observation for 6 months. The patient was satisfied with the treatment. Fig 6 gives an idea of how drastically the esthetics were changed with properly made complete overdentures for this patient. 


\section{DISCUSSION}

Ectodermal dysplasia is diagnosed intraorally by one of its main features that is hypodontia/anodontia. ${ }^{6}$ Sagittal and vertical relationships of somatognathic system are severely compromised in the patients of ectodermal dysplasia. ${ }^{7}$ Most often patients present with class III inter-maxillary relationship, prominent chin, loss of vertical relationship. ${ }^{8}$ Prosthetic management of patients suffering from orphan diseases like ectodermal dysplasia requires a challenging approach because of rarity of such syndromes. ${ }^{9}$ Multidisciplinary approach is recommended in such cases for treatment planning. 5,10

Dental literature reports different prosthetic treatment options to the oral rehabilitation of patients with ectodermal dysplasia. ${ }^{2-5}$ Removable prostheses is the most common treatment of choice. The lack of fully developed alveolar ridges, xerostomia and under-developed maxillary tuberosities result in poor support, retention and stability in conventional complete denture. Conical anterior teeth pose problem to the removable partial denture stability but they are suitable to be used as abutments for overdentures. ${ }^{8}$ Osseo-integrated implants is one of the treatment options in patients with ectodermal dysplasia but adequate bone volume is important for the successful placement of implants, which is mostly lacking in these patients. ${ }^{5,7}$

In this case report, implant placement was not considered as treatment of choice because of atrophic under-developed ridges and patient's economic status. Overdenture was a suitable choice in this specific case as anterior atypical conical teeth used as abutments to compensate the drawbacks related to retention, stability and support in the case of removable partial or conventional complete dentures. Rehabilitation of patient's function, esthetics and phonetics was up-to the mark and patient was truly satisfied with restored self-esteem.

\section{CONCLUSION}

Careful analysis of different phases of growth and development of craniofacial complex is required for oral rehabilitation of patients with ectodermal dysplasia. Toothsupported overdenture is most common and cost-effective treatment modality for the patients of ectodermal dysplasia. Care and maintenance of present natural teeth with adequate oral hygiene measures and topical fluoride prophylaxis is the key to the long-term success.

\section{CONFLICT OF INTEREST}

None declared

\section{REFERENCES}

1. Dogan MS, Akbaba MH, Yavuz I, Tanik A, Aras A, Demirci F et al. Oral Rehabilitation of Patients with Ectodermal Dysplasia: Cases Series. Int J Health Sci 2016;4:59-8.

2. Patidar C, Shigli A, Sharma DS, Kulkarni VK, Sharma S, Patidar C. Oral Rehabilitation of Hypohidrotic Ectodermal Dysplasia - A Case Report and Review. Ann. Prosthodont Resto Dent 2016;2:88-91

3. Pandey R, Khatri A. Dental Management of Ectodermal Dysplasia: A Report of Two Cases. Journal homepage: www. nacd. in Indian J Dent Adv 2017;9:191-96.

https://doi.org/10.5866/2017.9.10191

4. Koyuncuoglu CZ, Metin S, Saylan I, Calisir K, Tuncer O, Kantarci A. Full-mouth rehabilitation of a patient with ectodermal dysplasia with dental implants. J Oral Implantol 2014.

https://doi.org/10.1563/AAID-JOI-D-12-00072

5. Nallanchakrava S. Oral rehabilitation of a patient with ectodermal dysplasia with prosthodontics treatment. Indian J Dermatol 2013;58:241. https://doi.org/10.4103/0019-5154.110851

6. Hypodontia MA. Ectodermal dysplasia syndrome with cleft palate, hypodontia, metatarsus adductus and imperforate anus: a new syndrome? Pak Oral Dent J 2013;33.

7. Dental management of persons with ectodermal dysplasia. Position statement. ACP 2016.

8. Hekmatfar S, Jafari K, Meshki R, Badakhsh S. Dental management of ectodermal dysplasia: two clinical case reports. J Dent Res Dent Clin Dent Prospects 2012;6:108.

9. Schnabl D, Grunert I, Schmuth M, Kapferer-Seebacher I. Prosthetic rehabilitation of patients with hypohidrotic ectodermal dysplasia: A systematic review. J Oral Rehabil 2018;45:555-70.

https://doi.org/10.1111/joor.12638

10. Alowairdhi AA. Prosthodontic management of children with ectodermal dysplasia: A literature review. Saudi Dent J 2019. https://doi.org/10.1016/j.sdentj.2019.02.036 